\title{
The influence of selected teacher inputs on students' academic achievement in the junior secondary school certificate mathematics in Namibia
}

\begin{abstract}
SE AKPO AND LCJITA ${ }^{2}$
Abstract

This study explored the link between teachers' inputs and students' academic achievement in the JSC Mathematics for the period 2006 to 2010. One hundred and fifty secondary schools selected from 573 secondary schools in the country constituted the target population. One hundred and sixty-four JSC mathematics teachers from the 150 secondary schools participated in the study, with the final JSC Mathematics results of the students serving as the dependent variable of the study. Mathematics teachers' input data (academic qualifications, teaching experience and subject specialisation) were collected from a questionnaire developed by the researchers. Standard multiple regression was used to analyse the link between teachers' inputs and students' academic achievement in JSC Mathematics at $P<0.05$ and $\mathrm{P}<0.10$ respectively. The study found that teachers' academic qualifications and subject specialisation had a significant and positive relationship with students' academic achievement in JSC Mathematics. Teachers' gender, however, was not significantly related to students' academic achievement in JSC Mathematics. This is the first time within the Namibian context that we have empirically demonstrated the link between teachers' inputs and students' academic achievement in JSC Mathematics. The study therefore provides support for the policy initiatives that seek to link teachers' academic qualifications, subject specialisation and teaching experience to employment and classroom allocation.
\end{abstract}

Key words: teacher qualifications, teaching experience, subject specialisation, academic performance, Junior Secondary School Certificate, and mathematics achievement.

\section{Introduction}

Researchers continue to puzzle over the relationship between teacher inputs and behaviour and students' achievement (Hill, Rowan \& Ball, 2005). The measures of teacher inputs have varied widely, as have results from these investigations. Identification of teacher inputs and practices that contribute most towards improving students' achievement has often eluded researchers, even though most seem to believe that addressing weak teaching may be the most effective means of improving school quality (Glewwer \& Kremer, 2006). While numerous studies exist on the influence of specific teacher quality attributes on students' academic achievement, relatively few studies in the past twenty years have focused on exploring how

1. Simon E. Akpo (DEd) is an education consultant in Namibia. Emeil: seakpo@gmail.com

2. Corresponding author: Loyiso C. Jita $(\mathrm{PhD})$ is a Professor of Education in the School of Mathematics, Natural Sciences and Technology Education, University of the Free State. His research investigates the nature and manifestations of Instructional Leadership. Email: jitalc@ufs.ac.za 
teacher quality and teacher preparedness (professional development, curriculum knowledge, pedagogical knowledge and classroom management) affect students' academic achievement in secondary schools (Hill, Rowan \& Ball, 2005). In an attempt to provide research evidence in this area, we explored in this study the relationship between teacher inputs and students' academic achievement in mathematics in the Junior Secondary School Certificate examinations in Namibia.

\section{Context of the Study}

The Republic of Namibia is located on the south west coast of Africa, and is bordered by the Atlantic Ocean to the west, the Republics of Angola and Zambia to the north and north-east respectively, and the Republics of Botswana and South Africa to the east and south respectively. Formerly under the mandate of South Africa, Namibia gained independence in March, 1990. Namibia's population is estimated to be about 2 million (National Planning Commission (NPC), 2008). The country has 13 Regional Councils, with the Khomas Region being the largest in terms of population size. Windhoek, in the Khomas Region, is the capital of the country.

The education system of Namibia encompasses seven years of primary education (PE) catering for Grades 1-7, three years of junior secondary education (JSC) catering for Grades 8-10, and senior secondary education (SS) catering for Grades 11-12. Additionally, there are combined schools that cater for primary, junior secondary and/or senior secondary grades in one school. The Basic Education Teacher Diploma (BETD) is a 3-year programme offered at the four National Colleges of Education, while a 4-year Bachelor of Education (B. Ed) degree programme is offered at the University of Namibia. The Polytechnic of Namibia offers 3-year diploma programmes and 4-year Bachelor of Technology (B. Tech) degrees.

The National Institute for Educational Development (NIED) and the Directorate of National Examinations and Assessment of Namibia (DNEA), in conjunction with panels of subject experts on which the teachers are represented, are responsible for the development of syllabi, prescription of textbooks and provision of other learning resources (MoE, 2004). The DNEA is responsible for the setting and administration of examinations both for JSC in Grade 10 and IGSCE/ National Senior Certificate Examinations (NSCE) in Grade 12.

Students are admitted to the senior secondary level conditional on their scoring a minimum of 23 points or better in their six best subjects, including English Language (MoE/DNEA 2010).

\section{Statement of the Problem}

Secondary schools in Namibia have performed poorly in JSC, with the majority of the schools scoring below 50\% between 2000 and 2009 (MoE/EMIS, 2010). The trend in national performance in JSC mathematics results for 2000 to 2009 is presented in Table 1 below. 
Table 1: National Performance in JSC Results: 2000-2009

\begin{tabular}{l|l|l}
\hline National & $\begin{array}{l}\text { Percentage of grade D and better } \\
(50 \% \text { \& above })\end{array}$ & $\begin{array}{l}\text { Percentage } \\
\text { below D grade }\end{array}$ \\
\hline 2000 & 15.2 & 84.8 \\
\hline 2001 & 21.6 & 78.4 \\
\hline 2002 & 27.2 & 72.8 \\
\hline 2003 & 26.7 & 73.3 \\
\hline 2004 & 32.1 & 67.9 \\
\hline 2005 & 36.8 & 63.2 \\
\hline 2006 & 37.2 & 62.8 \\
\hline 2007 & 36.8 & 63.2 \\
\hline 2008 & 40.3 & 59.7 \\
\hline 2009 & 39.7 & 60.3 \\
\hline
\end{tabular}

(Source: Adapted From DNEA, 2010)

From Table 1 above, it is evident that the trend in national performance between 2000 and 2009 is not linear. The percentage of students who fell below the national requirements in mathematics for $2000-2009$ has hovered around $60 \%$ and higher, with a peak of about $85 \%$ in the year 2000. The poor performance of students in mathematics in secondary schools, as reflected by the JSC scores, is of particular concern as mathematics instruction during these years provides the foundation for success in Algebra. Algebra is fundamental to all areas of mathematics because it provides tools for representing and analysing quantitative relationships, for solving problems, and for stating and proving generalisations. Without proficiency in Algebra, students will be unlikely to master other mathematical subjects (Hill et al., 2005). This leads, in turn, to poor preparation for entry into tertiary institutions and thus closes off options for careers in mathematically related fields for many students.

Given the magnitude of this poor performance in Namibian secondary schools, it is imperative for specifically identified contributory factors and in particular the effects of teacher-related variables on students' achievement, to be examined empirically. It is this context that provided the primary motivation for this study.

In an effort to determine which teacher-related variables affect school success, as measured by students' achievement in the JSC Mathematics examination, the following question is posed: To what extent did the following teacher inputs (qualifications, field of specialisation, and years of experience) affect students' academic performance with regard to JSC Mathematics results for 2006-2010. More specifically, the study sought to explore how various aspects of teacher quality inputs; classroom practices and professional development influence one another and how these myriad influences impacted students' results in the JSC Mathematics examinations for 2006-2010. 


\section{Purpose of the Study}

The purpose of this study was to establish the extent to which teachers' inputs relate to students' academic achievements in JSC Mathematics. Furthermore, the study examined the contribution of each teacher's input in explaining the variance in students' academic achievement in JSC mathematics, and established the total variance that could be accounted for by these teachers' inputs using Standard Multiple Regression Analysis.

\section{Hypotheses of the Study}

The study tested the following hypotheses:

1. There is a statistically significant correlation at the 0.05 level between teacher experience and the achievement of students as measured by JSC Mathematics scores.

2. There is a statistically significant correlation at the 0.05 level between teacher level of education and the achievement of students as measured by JSC Mathematics scores.

3. There is statistically significant correlation at the 0.05 level between teacher subject specialisation and the achievement of students as measured by the JSC Mathematics scores.

\section{Review of Relevant Literature}

The researchers adopted an education production function to explore the link between teachers' inputs and students' academic achievement in JSC Mathematics. Greenwald, Hedges and Laine (1996) contend that production function is an important model which researchers and policymakers have used for over 20 years to analyse the impact of educational resources on student academic achievement. Monk (1994) discusses how researchers and policymakers have measured the influence of school characteristics, teacher characteristics, facilities, and student characteristics on students' academic achievement using the production function. He contends that the production function includes a wide range of areas that encompass educational production studies. For Monk (1994), educational inputs include school characteristics, teacher-related variables, facilities and students' characteristics. Greenwald et al. (1996) define outcomes as achievement as measured by standardised tests, future educational patterns, and adult learning. The literature thus suggests that the standard production function model is always expressed as an equation,

$\mathrm{Y}=\mathrm{f}(\mathrm{T}, \mathrm{P}$, and $\mathrm{S})$, where $\mathrm{Y}$ represents the educational outcomes variable (dependent variable), $\mathrm{T}$ represents teachers' inputs (independent variable), $\mathrm{P}$ represents school characteristics (independent variable), and S represents students' characteristics (independent variable). Since the purpose of the current study was to determine the impact of teachers' inputs on students' academic achievement, we opted to drop $\mathrm{P}$ and $\mathrm{S}$ in the equation and adopt a process-product model instead. A process-product approach uses teachers' inputs as the independent variable and students' academic achievement in JSC Mathematics as the dependent variable. In order to understand the extent to which the teacher inputs correlate with students' academic achievement in Mathematics, we first turn our attention to the empirical studies that link teachers' inputs with students' academic achievement in Mathematics at secondary school level. 


\section{Teachers' Academic Qualifications}

On the link between teachers' academic qualifications and students' academic achievement in Mathematics at secondary school level, Darling-Hammond's (1999) and Darling-Hammond and Sykes' (2003) findings suggest that teacher qualifications have a significant and positive correlation with student achievement. Furthermore, Darling-Hammond found that uncertified teachers and those with the most non-standard certifications had negative effects on student achievement gains. Darling- Hammond and Sykes (2003) conclude that, in the context of the United States of America (USA), qualified teachers are a critical national resource that requires federal investment and cross-state coordination as well as other state and local action. Similarly, Kaine, Rockoff and Staiger (2006) found that the proportion of lower-performing students at a school was related to the proportion of teachers at that school who were not certified to teach in any of the subjects which they were currently teaching. Boyd, Grossman, Lankford, Loeb and Wyckoff (2006) also found support for the view that teacher preparation programmes in either traditional or alternative pathways had an influence on student gains in New York State achievement tests. Rice (2003), however, provides a more measured conclusion that teacher certification seems to matter for high school mathematics with little evidence of its relationship to student achievement in the lower grades. Rice's position is somewhat bolstered by Goe (2007), who reported on a 2002 study on California schools to examine the relationship between the percentage of teachers holding emergency permit (EP) teacher certification and student achievement at school level which found a direct negative correlation between the two. Evidence on the link between teachers' academic qualifications and students' achievement thus remains contentious.

\section{Teachers' Teaching Experience}

With regard to teaching experience, it is important to bear in mind that some research has suggested that the positive effects of teaching experience in relation to students' achievement are not constantly additive, but instead tend to level off after a few years (Rivkin, Hanushek \& Kain, 2005). Greenwald, Hedges and Laine (1996) and Rice (2003) have demonstrated a significant and positive relationship between teachers' number of years of experience and student achievement. However, these authors argue that the relationship is not linear. It is important to balance these studies on teacher experience with the finding that teachers' effectiveness in improving student achievement appears to increase most in the first three years of teaching, but no major improvement in their effectiveness has been observed after three years of teaching experience (Boyd, Grossman, Lankford, Loeb \& Kain, 2005). Murnane (1995) supports the latter view by arguing that the typical learning curve for students' peaks in the teacher's first two years for reading and three years for mathematics.

\section{Teachers' Subject Specializations}

Several studies have demonstrated a positive relationship between teachers' subject specialization and student achievement. Betts et al. (2003) found that teachers with 
mathematics major had a positive impact on secondary students' achievement in that subject. Similarly, Goldhaber and Brewer (2000) found that students who had teachers with advanced subject-related degrees in mathematics and science performed better than students of teachers without subject training. The relationship between teachers' specialisation and student achievement was not the same throughout all levels of schooling. Monk and Rice (1994) found that even in subjects where subject-specific training may make a difference (e.g. mathematics); its impact depends on the type of classes taught (primary or secondary). The authors argue that the number of college mathematics courses taken by a teacher at university or college has an impact on high school students' mathematics achievement, but additional teacher coursework beyond that only matters if the teacher is teaching an advanced course beyond the secondary level.

\section{Methodology}

The researchers adopted ex-post-facto research design because the study sought to determine the relationship between existing teachers' inputs with students' academic achievements in JSC mathematics. The participants, 164 JSC mathematics teachers from 150 schools, were selected from a current list of 573 JSC schools stratified by region using systematic sampling with a random start. The researchers adopted a two-step sampling approach to select the 150 JSC secondary schools. In the first stage, units (regions) were selected using probability equal to one. This implies that all 13 educational regions were selected. In the second stage, the selection of 150 JSC schools from a current list of 573 JSC secondary schools stratified by region was made using systematic sampling with a random start. Self-administered questionnaires were distributed to the targeted JSC schools with help from trained assistants and the offices of the 13 Education Regional Directors. All eligible teachers in a school completed the questionnaire.

\section{Reliability and Validity of Instruments}

The items in the questionnaires were adopted from studies of Wenglinsky (2002), Akiba et al. (2008) and Ingvarson et al. (2009), as published in National Assessment of Educational Progress (NAEP) and Education Policy Analysis Archive (EPAA) that established a link between teachers' relative variables and students' academic achievement in Mathematics. These items were selected because they were reported to have a relationship with students' academic achievement in Mathematics in previous studies (see Darling-Hammond, 1999; Hanushek et al., 2005; Wenglinsky 2000, 2002 etc.). The reliability for the measure with this study sample was found to be 0.76 , calculated using Cronbach Alpha.

\section{Data Collection Methods}

The students' academic results in JSC Mathematics (2006 - 2010) were obtained from the Directorate of National Examinations and Assessment (DNEA) in Windhoek, Namibia. The information about teachers' inputs (teachers' educational qualifications, teaching experience, was obtained through the self-administered questionnaires. The dependent 
variable was the average score of a school in JSC mathematics results in the years 2006 to 2010. Each school was used as a unit of analysis.

Academic achievement was determined for each school by getting the cumulative percentage for all the students in that particular school that got a grade " $\mathrm{D}$ " or better. The JSC grading points system is as follows: A (70\%-100\%), B (60\%-69\%), C (50\%-59\%), D (40\%-49\%), and E (30\%-39\%) F (20\%-29\%), G (10\%-19\%), and U (0\%-9\%). The final academic achievement was computed by aggregating the scores for 2006-2010.

\section{Average Pass Rate per School}

Students' academic achievement (performance) is represented by the average pass rate for each school over the years 2006-2010. The average pass rate was captured as follows

$$
\overline{X_{s}} \quad=\quad \frac{\sum_{t=2006}^{2010} p_{t}}{n} \quad \text { or } \quad \overline{X_{s}}=\frac{\left(P_{2006+} P_{2007+} P_{2008+} P_{2009+} P_{2010}\right)}{5}
$$

Where:

$\bar{x}_{s}=$ The average performance (pass rate for a grade $\mathrm{D}$ or better) for each school (JSC mathematics teacher).

$\bar{x}_{s}=$ The dependent variable, students' academic achievement in JSC mathematics, which the researchers used to find the correlations with other teachers', constructs (independent) variables.

\section{Data Analysis}

The researchers did a 3-step analysis of the data using both descriptive and inferential statistics.

First, we used descriptive statistics to explore the teachers' biographic characteristics by gender, subject specialization, teaching experience, academic and professional qualifications.

Then we then did a correlation analysis to identify the extent of the relationship between the students' achievement and the independent variables (teachers' inputs). In the last stage, a standard multi regression analysis was used to test the relationship between teachers" inputs and students' JSC academic results in 150 schools. The output of the standard multiple regression analysis helped to shed light on how the variables that significantly affect students' academic gains as identified in stage 2 could predict students' achievement.

\section{Standard Multiple Regression Assumption Analysis}

Keith (2006) contends that the assumption of Multiple Regression (MR) is the most significant because it directly relates to the bias of results for the entire analysis. The assumption includes linearity (dependent variable as a linear function of independent variable), Multicollinearity (independent variables are uncorrelated), Normality (variables 
have normal distributions), and Homoscedasticity (equal variance of errors across all levels of response variables-independent variables).

\section{Linearity test}

Using the SPSS for scatter plots diagrams, we found that the residuals were randomly scattered around the horizontal line.

\section{Homoscedasticity test}

We used a statistical software scatterplots of residuals, and found that the variance of the residuals about the predicted responses were the same for all predicted responses.

\section{Multicollinearity Test}

Keith (2006) maintains that multicollinearity occurs when one independent variable is almost a linear combination of other independent variables. Using the SPSS software, we found that the Variance Inflation Factor(VIF) values for all independent variables (teachers' inputs) was less than 1.0 and more than 0.1 Tolerance Value(TV).

\section{Normality Test}

Keith (2006) argues that normality of data implies that the residuals should be normally distributed about the predicted responses, and a plot of the values of these residuals will approximate a normal curve. Using the SPSS software to generate P-Plot, the researchers found that the plotted values for residuals were almost normally distributed about the predicted responses.

From the above tests, it is evident that the assumptions of the regression model have been met, thus the next section presents the results and discussions based on the Standard Multiple Regression Analysis (SMRA).

\section{Explanation on Omitted Variables}

The students JSC academic achievement in mathematics results depend on a combination the current and past education inputs. This combination of past and current educational inputs can be represented by a general education production function as:

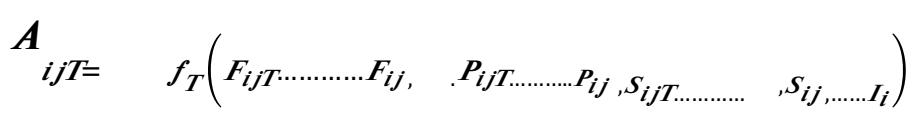

Where $A_{i j T}$ represents the academic achievement for $i^{\text {th }}$ student at school $\mathrm{j}$ at time $\mathrm{T}$. The capital letter $\mathrm{T}$ represent the current time and small $\mathrm{t}=0$ represent the time interval prior to the time the student enters JSC school, $\mathrm{t}=1$ correspond the first year of JSC (grade8), and $\mathrm{t}=2$ correspond to second year of JSC (grade9) and $t=3$ corresponds to year 3 (grade 10). The symbol $F_{i j T}$ represents family background of JSC student, $P_{i j T}$ represent peer (community 
factors); $S_{i j T}$ represents school inputs (inputs of JSC teachers) and $I_{i}$ represent unobserved innate abilities.

To account for omitted variables such as students, innate ability, peer effect, school characteristics and students background information, we adopted the contemporaneous educational production function. The adoption of this model is based on Todd and Wolpin's (2003) and Ding and Lehrer's ( 2008) assumptions that; the effects of past educational inputs and unobserved innate ability in the production process decay immediately and contemporaneous inputs are unrelated to unobserved innate ability and unobserved past educational inputs.

Thus, in this study we concentrated only on the link between teachers' inputs (educational qualifications, teaching experience, and subject specialisation) and students' academic achievement in JSC mathematics results. Additionally, only teachers who taught JSC mathematics for at least three consecutive years in the same Grade 10 were considered for the study.

\section{Results and Discussions}

Table 2: Model Summary

\begin{tabular}{l|l|l|l|l}
\hline $\mathrm{R}$ & R Squared & $\begin{array}{l}\text { Square Adjusted R } \\
\text { Standard Error of }\end{array}$ & $\mathrm{F}$ & $\mathrm{P}$ \\
\hline .39 & .0 .15 & .0 .18 & 6.39 & .042 \\
\hline
\end{tabular}

*Significant at $P<0.05 ; \mathrm{F}(4 ; 145)=6.39$

Table 2 reveals that the teachers' inputs made a contribution of $15.9 \%$ on students 'academic achievement in JSC mathematics. It implies that $84.1 \%$ unexplained factors that influenced students' JSC mathematics results are beyond teachers' inputs (teachers, teaching experience, subject specialization, academic achievement and gender). The F-value (6.39) which is significant at $0.05(P<0.05)$ reveals that the joint effects of teachers' inputs on students' academic achievement in JSC mathematics is significant.

Table 3: The Parameter Estimates of Teachers' Inputs on Students' Academic Achievement in JSC Mathematics

\begin{tabular}{llllll}
\hline \multirow{2}{*}{ Model } & \multicolumn{2}{l}{$\begin{array}{l}\text { Unstandardized } \\
\text { Coefficients }\end{array}$} & \multicolumn{2}{l}{ Standardized Coefficients } & \\
\cline { 2 - 6 } & & Std. Error & Beta & $\mathrm{t}$ & $\mathrm{p}$ \\
\hline Constant & 0.55 & .10 & & 5.50 & $0.000^{* * * *}$ \\
Teaching experience & 0.39 & 0.16 & 0.19 & 2.44 & $0.04^{*}$ \\
Academic Qualifications & .59 & 0.15 & 0.37 & 3.93 & $0.09^{* *}$ \\
Subject specialisation & 0.48 & 0.17 & 0.47 & 2.82 & $0.05^{*}$ \\
Gender & 0.03 & .02 & 0.33 & 1.50 & 0.51 \\
All constructs & 0.40 & 0.13 & 0.46 & 3.08 & $0.03^{*}$
\end{tabular}

\section{Significant at $P<0.05 ; \mathrm{t}(149 ; 0.025)=1.976$}

Table 3 depicts the relative contribution of each teachers' input variable on students 'academic achievement in JSC mathematics. Teaching experience $(=0.39 ; \mathrm{t}=2.44 ; \mathrm{P}<0.05)$, 
academic qualifications $(=.59 ; \mathrm{t}=3.93 ; \mathrm{P}<0.10)$, and subject specialisation $(=.48 ; \mathrm{t}=2.82 ; \mathrm{P}<$ 0.05 ), had a significant positive relationship on students" academic in JSC mathematics. The teachers' gender had a negative relationship with students' academic achievement in JSC mathematics. The beta values of the model revealed that teachers' academic qualifications contributed most (59\%) in students 'academic achievement, followed by subject specialisation $(48 \%)$ and teaching experience (39\%) in order of rank.

\section{Demographic Characteristics of JSC Mathematics Teachers}

The study required data on JSC mathematics teachers' demographic characteristics in order to assist in classifying them, for us to use the data to establish the extent of the relationship between teachers' data and students' academic achievement in JSC mathematics. Table 4 below provides detailed statistics on teachers' demographic characteristics by gender, subject specialisation, teaching experience, and academic and qualifications:

Table 4: Demographic Characteristics of JSC Mathematics Teachers

\begin{tabular}{l|l}
\hline Gender(n=144) & Percentage \\
Male & $87(60.4 \%)$ \\
Female & $57(39.6 \%)$ \\
Subject specialisation(n=164) & Percentage \\
Mathematics major & $153(93.3 \%)$ \\
Non-mathematics major & $11(6.7 \%)$ \\
Teaching Experience(n=160) & Percentage \\
Less than 2 years & $19(11.9 \%)$ \\
2-5 years & $52(32.5 \%)$ \\
6-9 years & $36(22.5 \%)$ \\
10 years and above & $53(33.1 \%)$ \\
Academic qualifications(n=160) & Percentage \\
1-2 year training certificate & $4(2.5 \%)$ \\
3 year training diploma & $92(57.5 \%)$ \\
4 year Bachelor's/Honour degree & $53(33.1 \%)$ \\
5 years or Master's degree & $3(1.9 \%)$ \\
Other & $8(5.0 \%)$ \\
Professional qualification(n=151) & Percentage \\
No teacher training & $7(4.6 \%)$ \\
1-2 year teacher training certificate & $43(28.5 \%)$ \\
3 year teacher training certificate & $46(30.5 \%)$ \\
4-5 year teacher training certificate & $32(21.2 \%)$ \\
Other & $23(15.2 \%)$ \\
& \\
\hline
\end{tabular}

From Table 4 above, it is evident that the majority of the JSC mathematics teachers were male, and constituted $60.4 \%$ of the teachers in this study. Also, 153 (93.3\%) of the teachers majored in mathematics (diploma and Bachelor's degree levels inclusive). Furthermore, Table 2 reveals that $53(33.1 \%)$ of the teachers had taught JSC mathematics for more than 10 years, while $52(32.5 \%)$ and $36(22.5 \%)$ of the teachers had taught JSC mathematics for 25 years and 6-9 years respectively. 


\section{Research Hypotheses}

The Standard Multiple Regression Analysis data in Table 3 were used to test hypotheses 1 to 3. The detailed analyses for each of the hypotheses are presented below.

\section{Hypothesis 1}

There is significant correlation at the 0.05 level between teacher experience and the achievement of students as measured by JSC mathematics scores.

As indicated in Table 3, the regression coefficient values obtained for teaching experience variable is 0.39 , implying that if other teacher variables are held constant and the teachers' teaching variable increased by one unit value, then the students' achievement in JSC mathematics will increase by 0.39 . The beta coefficient value, and $\mathrm{p}$-value for the relationship between teaching experience and students' achievement in mathematics were $(=0.39$; $\mathrm{t}=2.44 ; \mathrm{p}=0.04)$. As the probability is less than the $5 \%$ significance criterion that was employed, the null hypothesis is rejected and the alternate hypothesis is accepted. From the findings of this study, it is evident that there was a significant positive relationship between teachers' teaching experience and students' JSC mathematics results at $\mathrm{P}<0.05$. The $\mathrm{P}-$ value of 0.04 implies that there was a $4 \%$ chance that the relationship emerged randomly and a $96 \%$ chance that the relationship is real.

\section{Hypothesis 2}

There is statistically significant correlation at the 0.05 level between teachers' level of education and the achievement of students as measured by JSC mathematics scores.

Based on Table 3, it is evident that the regression coefficient value obtained for teachers' academic qualifications of 0.59 means that if other independent variables are held constant and teacher academic qualifications increased by one unit value, then the students' achievement in JSC mathematics will increase by 0.59. The results in Table 3 show that there was a moderate positive and significant relationship between teachers' academic qualification and students' JSC mathematics results. The p-value of 0.09 is less than $10 \%$ $($ Alpha $=0.1)$, and $\mathrm{t}=3.9$ is greater than the $\mathrm{t}$-table $=1.976$. The researchers therefore conclude that there is a significant positive relationship between teachers' educational qualifications and students' academic achievement in JSC mathematics. The P-value of 0.09 implies that there was a $9 \%$ chance that the relationship emerged randomly and a $91 \%$ chance that the relationship is real. Hence, we conclude that there was a significant relationship between the teachers' academic qualifications and students' JSC mathematics results.

\section{Hypothesis 3}

There is statistically significant correlation at the 0.05 level between teacher subject specialisation and the achievement of students as measured by the JSC mathematics scores.

Based on Table 3, the regression coefficients value obtained for subject specialisation of 0.48 means that if other independent variables are held constant and the teacher subject specialisation variable is increased by one unit, the achievement of students in JSC mathematics will increase by 0.48 . As the probability is the null hypothesis is rejected and the alternate hypothesis is accepted 5\% significance criterion that was employed, and $t=2.8$ value 
is greater than $\mathrm{t}$-table value $=1.976$, we conclude that there was a significant relationship between teachers' subject specialisation and students' achievement in JSC mathematics at $\mathrm{P}<$ 0.05 . The $\mathrm{P}$ - value of 0.05 implies that there was a $5 \%$ chance that the relationship emerged randomly and a $95 \%$ chance that the relationship is real.

\section{Discussions of the Findings}

The study investigated the extent to which teachers' inputs (teaching experience, academic qualification, subject specialization and gender) influence students' academic achievement in JSC mathematics. The findings from the correlation analysis in Table 3 confirmed that teachers' experience, academic qualification, and subject specialisation had a moderate positive and significant relationship with students' achievement in JSC mathematics. The findings of this study confirmed the findings of Adeyemi (2010), and Yara and Catherine (2011), that teachers' teaching experience and academic qualifications were most important predictors of students' academic achievement. However, this study found that teachers' gender did not have a significant effect on students' academic achievement in JSC mathematics. The findings correspond with those of Akiri and Ugborugbo (2008), who found that there was no significant relationship between teachers' gender and students' academic achievement.

With regards to teachers' teaching experience, the findings of this study concur with Goe (2007), Kane, Rockoff and Staiger (2006) and Darling-Hammond (1999) that teachers' teaching experience have a significant positive influence on students' achievement in mathematics within the first four or five years. While the null hypothesis is rejected and the alternate hypothesis is accepted, findings provide some support for trying to retain experienced teachers in the teaching profession. These results cannot be interpreted to mean that in general the most highly experienced teachers are significantly more effective than teachers with limited experience.

As per demographic characteristics of JSC mathematics teachers, the descriptive statistics in Table 2 reveal that 153 (93.3\%) teachers majored in mathematics at both BETD and B.Ed. Honours levels, and $92(57.5 \%)$ and $53(33.1 \%)$ had either three-year diploma training or a four-year academic degree respectively. Almost $80 \%$ of the teachers were professionally trained. This implies that the JSC mathematics teachers were exposed to mathematical content knowledge (MCK) and pedagogical content knowledge (PCK) at the under-graduate levels, but that such training did not seem to have a strong significant relationship with students' achievement in JSC mathematics.

These findings may seem to confirm somewhat the reports of the NCHE (2007) and MoE (2011) which noted weaknesses in the Namibian BETD mathematics education programmes; viz. that teachers' lack of competence is due to inadequate training at the lower level, the inadequacy of the structure and curriculum of BETD programmes in equipping teachers with competency in content and pedagogical knowledge, particularly in terms of school-relevant subject content, and the inefficiency of the teaching methods advocated for mathematics. The statistics in Table 2 reveal that $93.3 \%$ of the teachers majored in mathematics at both diploma and degree level, but this does not seem to have influenced student achievement in this case. Additionally, there is evidence to suggest that the mathematics training programmes for the BETD are lacking in both MCK and PCK. For 
example, the studies of the NCHE (2007), Marope (2005), and MoE (2011) revealed that the BETD programme was very weak in both these aspects. Is it likely then that part of the problem could possibly be attributed to lack of $\mathrm{MCK}$, or lack of mathematical PCK, or nonalignment of the curriculum with the content knowledge? More research is required on this aspect.

\section{Conclusion}

This paper has discussed the extent to which teacher-related variables correlate with student achievement in JSC mathematics in Namibia. The results demonstrate that there is a significant, although moderate, relationship between teachers' teaching experience, academic qualifications and subject specialization and students' achievement in JSC mathematics. However, teachers' gender did not have any significant relationship with students' academic achievement in JSC mathematics. These are significant findings that have not previously been empirically demonstrated in the context of Namibia and other African countries. Further research is needed to confirm the findings both in Namibia and in other African countries.

Due to the positive and significant relationship that has been demonstrated between teacher variables and student achievement, the findings from this study may be of benefit to policymakers and researchers who may want to implement effective teacher-training programmes that target the improvement of the identified teacher variables. It is hoped that the findings of this study will motivate a concerted effort from all stakeholders in education towards the on-going improvement of mathematics education in Namibia and elsewhere.

\section{Recommendations}

In reading the findings of this study, it is important to bear in mind the one key limitation of the research: that the study employed only a structured questionnaire (closed-ended) to capture the teacher-related variables. Self-reported data on teachers' inputs do not provide a full picture of how teachers' inputs impact students' academic achievement in mathematics at JSC level. Other data collecting methods and instruments need to be designed to get the full picture of the relationships. Direct assessment of teachers' actual mathematical knowledge, for example, provides the strongest indication of a relation between teachers' content knowledge and their students' academic achievement. More precise measures are needed to specify in greater detail the relationship between the JSC teachers' mathematical knowledge, their instructional skills and students' academic achievement. A mixed-method study, for instance, may be considered for an in-depth analysis of the impact of teachers' inputs on student academic achievement in JSC mathematics in Namibia.

\section{References}

Adeyemi, B. (2010). Teachers' Related Factors as Correlates of Pupils Achievement in Social Studies in South West Nigeria. Electronic Journal of Research in Educational psychology, 8(1): 313-332.

TD, 9(3), Spec. ed, December 2013, pp. 465-479. 
Akiri, A.A. and Ugborugbo, N. M. (2008). An Examination of gender Influences on Teachers' Productivity in Secondary Schools. Journal of Social Sciences, 17(3): 185-191.

Akiba, M., Chiu, Y-F., Zhuang, Y., \& Eastman-Mueller, H. (2008). An Examination of gender Influences on Teachers' Productivity in Secondary Schools. Journal of Social Sciences, 17(3): 185-191.

Betts, J.R., Zau, A.C., and Rice, L.A... (2003).Determinants of Students achievements: New Evidence from San Diego. San Diego: Public Policy Institute of California.

Boyd, D., Grossman, P., Lankford, H., Loeb, S., \& Wyckoff, J. (2006).How changes in entry requirements alter the teacher workforce and affect student achievement. Albany, NY: Teacher Policy Research.

Darling-Hammond, L. (1999).Teacher quality and student achievement: A review of state policy evidence. Washington, University of Washington: Centre for the Study of Teaching and Policy.

Darling-Hammond, L. and Sykes, G. (2003). Wanted: A national teacher Supply policy for education: The right way to meet the "Highly Qualified Teacher" challenge. Education Policy Analysis Archives, 11(33), 1-50.

Ding, W. And Lehrer, S. F. (2008). Accounting for Time- Varying unobserved ability heterogeneity within education production functions. Queen's University and NBER.

Glewwer, P., and Kremmer, P. (2006). Schools, teachers and education outcomes in developing countries, in E. Hanushek and F. Welch (Eds.), Handbook of the Economics of Education (pp. 945 - 1017). Amsterdam: Elsier.

Goe, L. (2007). The link between teacher quality and student outcomes: A research synthesis. Washington, DC: National Comprehensive Centre for Teacher Quality.

Goldhaber, D.D., \& Brewer, D.J. (2000).Does teacher certification matter? High school certification status and student achievement. Educational Evaluation and Policy Analysis.22, 129 - 146.

Greenwald, R., Hedges, L.V., and Laine, R.D. (1996).The effects of school resources on student achievement. Review of Educational Research, 66(3), 361 - 396.

Hill, H.C., Rowan, B., and Ball, D.L. (2005).Effects of teachers' Mathematical Knowledge for teaching on student achievement. American Educational Research Journal, 42(2), 371-406.

Ingvarson, L., Meiers, M. \& Beavis, A. (2005). Factors affecting the impact of professional development programmes on teachers' knowledge practice, students outcomes and efficacy. Educational Policy Analysis 13, (10). Retrieved July 17, 2012 from http://epaa.asu.edu/epaa/v13n10/.

Kane,T.J, Rockoff, J.E, \&Staiger, D.O. (2006). What does certification tell us about teacher?

Effectiveness? Evidence from New York City (NBER working Paper No.W12155). Cambridge, MA: National Bureau of Economic Research.

Keith, T. (2006).Multiple regression and beyond. MA: Pearson Allyn and Bacon

Lankford, H., Loeb, S. \&Wyckoff, J. ((2002). Teacher sorting and the plight of Urban Schools: A descriptive analysis. Educational Evaluation and Policy Analysis, 24:33-65. 
Marope, M.T. (2005). Namibia human capital and knowledge development for economic growth with equity, Africa Region Human Development Working Paper Series, No. 84, The World Bank: Washington DC.

Ministry of Education (MoE) (2004). Structure of the Ministry of Education. Retrieved October 2, from on http://www.op.gov.na/Decade_peace_edu.htm

Ministry of Education (MoE) (2010). EMIS Education Statistics. MoE: Windhoek, Namibia.

Ministry of Education (MoE) (2011).Collective delivery of the Education promises: improving the education and training systems for quality learning outcomes and quality of life. Presented at the National Education conference, 27June-1 July 2011, Windhoek, Namibia.

Monk, D.H. (1994). Subject area preparation of secondary Mathematics and Science teachers and student achievement. Economics of Education Review,13(2), 125 - 145.

Monk, D.H., and King, J (1994).Multi-level teacher resource effects on pupil performance in secondary Mathematics and Science: The Role of teacher subject-matter preparation in contemporary policy issues: choices and consequences in Education, edited by Ronald Ehrenberg. Ithaca, NY: ILR Press.

Murname, R., Willett, J., and Levy. (1995).The growing importance of cognitive skills in wage determination. The review of economics and statistics, 77(2), 248-270.

Nation Council of Higher Education (NCHE) (2007) Consultancy to develop guidelines on teacher education reform in Namibia, Windhoek Namibia.

NPC (September, 2008). Second Millennium Development goals Report/Namibia: Progress at Mid-Term September, 2008.

Rice, J. K. (2003).Teacher qualities: understanding the effectiveness of teacher attributes. Washington, DC: Economic Policy Institute.

Rivkin, S. G., Hanushek, E.A., and Kain, J. F. (2005).Teachers, schools, and academic achievement. Econometrica, 73 (2), 417-458.

Todd, P.E. and Wolpin, K.I. (2003). On the specification and estimation of the production function for cognitive Achievement. The Economic Journal 113 (485):F3-F33.

Wenglinsky, H. (2000). How teaching matters: Bringing the Classroom back into discussions of teacher quality. Princeton, NJ: Educational Testing Service.

Wenglinsky, H. (2002). The link between teacher classroom practices and student academic performance. Educational Policy Analysis Archives, 10(12).

Yara, P. O.and Catherine, W.W. (2011).Performance determinants of Kenya Certificate of Secondary Education in Mathematics in secondary schools in Nyamira Division, Kenya. Asian Social Science, 7(20): 107-112. 